\title{
Phytochemical analysis and anti-inflammatory activity of Cladophora aegagropila extract
}

\author{
Aleksandra Aleksandrova $^{(\mathbb{1}}$, Mariia Nesterkina $^{{ }^{*}}{ }^{\mathbb{D}}$, Svitlana Gvozdii $^{2}{ }^{\mathbb{D}}$, Iryna Kravchenko $^{1}{ }^{(\mathbb{D}}$ \\ ${ }^{1}$ Department of Organic and Pharmaceutical Technologies of Odessa National Polytechnic University, Odessa, Ukraine \\ ${ }^{2}$ Department of Human Health and Civil Safety, I.I. Mechnikov Odessa National University, Odessa, Ukraine
}

\section{A R T I C L E I N F O}

Article Type:

Short Communication

Article History:

Received: 19 April 2019

Accepted: 17 July 2019

Keywords:

Cladophora aegagropila

Phytochemical analysis

Anti-inflammatory activity

\begin{abstract}
A B S T R A C T
Introduction: The aim of this research is centered on phytochemical analysis and antiinflammatory activity of Cladophora aegagropila extract.

Methods: Total flavonoid content in the appropriate ethanol extract of $C$. aegagropila was determined using spectrometric method. Anti-inflammatory activity was evaluated by the models of carrageenan-induced and allyl isothiocyanate-induced (AITC-induced) inflammation of hind limb in rats. Experimental animals were divided into 3 groups, 5 animals each: $1^{\text {st }}$ group - control; the animals without therapy of induced inflammation, $2^{\text {nd }}$ group animals were treated with application of $5 \%$ ointment containing C. aegagropila; $3^{\text {rd }}$ group animals were treated with application of $5 \%$ ibuprofen. Evaluation of anti-inflammatory activity was performed by determination of dynamic change of thickness and volume of affected animal limb for carrageenan-induced inflammation for 8 days (with daily registration of records), and for AITC induced inflammation for $24 \mathrm{~h}$ (with registration of records after $30 \mathrm{~min}, 1 \mathrm{~h}, 2 \mathrm{~h}, 3 \mathrm{~h}$, $6 \mathrm{~h}$ and $24 \mathrm{~h}$ since phlogogen was introduced).

Results: Flavonoids content in C. aegagropila extract varied depending on ethanol concentration: usage of $40 \%$ ethanol led to $18.2 \mathrm{mg}$ of flavonoid recovery on $1.0 \mathrm{~g}$ of dry raw material; $70 \%$ ethanol $-39.5 \mathrm{mg}$ and $96 \%$ ethanol $-35.5 \mathrm{mg}$. Therapy of $5 \%$ ointment based on C. aegagropila extract decreased inflammatory response caused by subplantar introduction of corresponding phlogogen.

Conclusion: The ointment from C. aegagropila extract shows anti-inflammatory activity by inhibiting inflammation caused by AITC and carrageenan.
\end{abstract}

Implication for health policy/practice/research/medical education:

Cladophora aegagropila extract possesses significant anti-inflammatory action and might be used as an effective natural agent for inflammation treatment.

Please cite this paper as: Aleksandrova A, Nesterkina M, Gvozdii S, Kravchenko I. Phytochemical analysis and antiinflammatory activity of Cladophora aegagropila extract. J Herbmed Pharmacol. 2020;9(1):81-85. doi: 10.15171/jhp.2020.12.

\section{Introduction}

Despite vast experimental and clinical experience, there is a problem of inflammatory processes that remain in the modern theoretical and experimental medicine. Inflammation is a pathological process that develops in case of tissue damage and involves in disturbed circulation, blood and connective tissue changes by alteration, exudation, proliferation. Sense of this pathology is a cascade of cause-and-effect process that elements of damage and defence are always present. Pharmacological regulation is one of the most difficult and the least developed problems of modern pharmacology. Therapy of inflammation is focused on elimination or limitation of lesion and its pathogenic agents $(1,2)$.

Intensive development of chemistry of the synthetic medicine cannot eliminate the practical need of the herbal medicinal products. Both of these sources enrich and expand the assortment of medication for medical therapy. Algae is actively used as herbal remedy for obtaining the biological active substances (BASs) in medicine. Various investigations have demonstrated that algae has antiinflammatory, analgesic, anticancer and regenerative activities. Korean scientists showed that usage of Laminaria japonica led to the inhibition of carrageenan- 
induced oedema and infiltration of inflammatory cells in the active phase of inflammation by inhibition of TNF- $\alpha$, interleukin- $1 \beta$ and interleukin-6 production (3).

It has been shown that Dichotomaria obtusata possesses dose-dependent anti-inflammatory and analgesic activities based on the model of mice (4). Anti-inflammatory action of sulphate polysaccharide complex of fucoidan obtained from such algae as L. japonica and Cladosiphon okamuranus and extract of Cistanche tubulosa by their synergy was shown in vitro and in vivo (5).

Our attention settled on the alga Cladophora aegagropila that lives in the Black Sea. Therefore, the aim of this research is centered on phytochemical analysis and antiinflammatory activity of $C$. aegagropila extract.

\section{Materials and Methods}

Extract preparation

Ten grams of dried (at room temperature) and milled raw material from alga that passed through a $2 \mathrm{~mm}$ sieve, was then extracted with $50 \mathrm{ml}$ of ethanol with different concentration (40, 70 and 90\%, appropriately). Extraction was carried out during 14 days by infusion at room temperature without access to direct sunlight. The obtained extracts were filtered and filled up to original volume by corresponding solvent. Then, the flavonoid content of the extracts was determined. Total flavonoid content as rutin equivalent in an ethanol-aqueous extract was performed using spectrometric method $(6,7)$. The method was based on the flavonoids ability to form complexes with aluminium chloride solution in ethanolaqueous medium. Measurement of optical density of tested solutions was performed in $413 \mathrm{~nm}$ with length of the absorbing layer $10 \mathrm{~mm}$ using spectrometer UV2401PC (Shimadzu, Japan).

Dry extract was used for 5\% ointment compounding. Calculated amounts of corresponding extract were introduced into the ointment base containing from a mixture of polyethylene glycol (PEG 1500), polyethylene oxide (PEO 400) and 1,2-propylene glycol, taken in mass ratios of 3:4:2 $(8,9)$.

Wistar rats weighing 180-200 $\mathrm{g}$ were used for experiment. Anti-inflammatory activity of the obtained $5 \%$ ointment was studied on the model of carrageenaninduced inflammation (10,11). Therefore, $0.2 \mathrm{~mL}$ $0.2 \%$ aqueous solution of carrageenan was introduced subplantarly (sub-plantar aponeurosis) into the left hind limb of the rat. Experimental animals were divided into 3 groups, 5 animals each:

- $1^{\text {st }}$ group - control, the animals with induced inflammation without therapy;

- $\quad 2^{\text {nd }}$ group - animals were treated with application of $5 \%$ ointment containing C. aegagropila on the affected limb during 4 days after the start of inflammation;

- $3^{\text {rd }}$ group - animals were treated with application of $5 \%$ ibuprofen on the affected limb during 4 days after the start of inflammation.

Measurements of width and volume of the affected rats' limbs were conducted for evaluation of antiinflammatory activity daily for 8 days. For evaluation of anti-inflammatory activity using model of AITC-induced inflammation $(8,12)$, the rats were similarly divided into groups.

- 1 st group - control, animals without therapy.

- 2nd group - animals treated with the application of $5 \%$ ointment 1 hour and 24 hours prior AITC introduction into the hind limb.

- $\quad 3$ rd group - animals were similarly treated with $5 \%$ ibuprofen ointment.

After subplantar introduction $30 \mu \mathrm{l}$ of AITC solution in 1,2-propyleneglycol (dose of $100 \mathrm{mg}$ per rat's limb), $2^{\text {nd }}$ animal group had therapy of obtained ointment. Thickness and volume of the affected limb was measured in animals from both groups after $30 \mathrm{~min}, 1 \mathrm{~h}, 2 \mathrm{~h}, 3 \mathrm{~h}$, $6 \mathrm{~h}$ and $24 \mathrm{~h}$ after phlogogen introduction using digital calliper and plethysmometer correspondingly.

Statistical analysis of the obtained results was made by $t$ test (following Student's $t$-distribution), arithmetic mean, standard deviation, validity coefficient in order to establish the presence of statistically significant differences between the values of experimental and control animals.

\section{Results}

Quantitative flavonoid content in C. aegagropila extracts depending on ethanol concentration was established. As it is apparent from the presented data (Table 1), usage of $70 \%$ ethanol as an extractant in maceration provided the maximum flavonoids extraction from C. aegagropila. Based on the obtained data, $5 \%$ hydrophilic ointment in terms of a dried extract containing $2 \mathrm{mg}$ of flavonoids per $1 \mathrm{~g}$ of extract was developed.

Anti-inflammatory action of the obtained ointment was evaluated using the model of carrageenan-induced inflammation. Inflammation was observed after phlogogen introduction resulting in erythema and increasing of volume and thickness of affected rat's limb (Figure 1).

After 2 days of ointment application reduction of the volume of the affected limb was occurred by $24 \%$ according to the values of animals without treatment. After 4 days of ointment application the reduction of inflammatory reaction (volume of affected limb) was occurred by 30\%$39 \%$ comparing to non-treated animals. After 7-8 days of the experiment the values of the volume of affected limb almost returned to the normal intact values. Application

Table 1. Flavonoid content in Cladophora aegagropila extracts depending on ethanol concentration

\begin{tabular}{lccc}
\hline & \multicolumn{4}{c}{ Flavonoids, } & mg per 1 $\mathbf{g}$ of dried alga \\
\cline { 2 - 4 } Ethanol & $\mathbf{4 0 \%}$ & $\mathbf{7 0 \%}$ & $\mathbf{9 6 \%}$ \\
\hline Quantity & $18.2 \pm 0.2$ & $39.5 \pm 0.4$ & $35.5 \pm 0.4$ \\
\hline
\end{tabular}



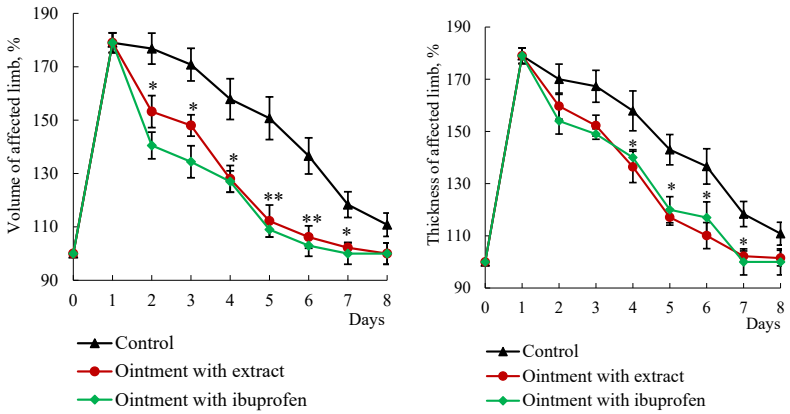

Figure 1. Anti-inflammatory activity of $5 \%$ ointment with extract and $5 \%$ ointment with ibuprofen using carrageenan-induced inflammation $\left(\mathrm{M} \pm \mathrm{m}, \mathrm{n}=5 ;{ }^{*} P<0.05,{ }^{* \star} P<0.01\right.$ compared to the control group with inflammation).

of 5\% ibuprofen ointment during the whole experiment provided essentially the same identical anti-inflammatory activity except 2 and 3 days of the experiment, in which ibuprofen was more effective compared to ointment with C. aegagropila extract.

Dynamic change of second morphological factor - thickness of affected limb - also demonstrated antiinflammatory activity of ointment starting from the third day and until the end of experiment (significant difference of values from non-treated animals). Anti-inflammatory activity of experimental ointment during the whole experiment was on a level with action of the reference medicine.

Anti-inflammatory activity of the ointment using the model of AITC-induced inflammation was also investigated. Subplantar introduction of AITC into the rat's hind limb led to increase of the morphological characteristic of the limb (Figure 2). The increasing of the volume and thickness of affected limb occurred in the non-treated animals and the growth was registered by $96 \%$ and $50 \%$ prospectively after $30 \mathrm{~min}$ according to the measurements of the intact values of the rat's limbs.

Both volume and thickness gain of affected limb, indicating inflammation, achieved their maximum values $2 \mathrm{~h}$ after the phlogogen introduction and achieved 100\% and $66 \%$ prospectively to intact values of limbs.

Pre-application of ointment on the limb prior AITC introduction and subsequent treatment of the affected limb after phlogogen introduction led to inflammation reduction. Hence, after $30 \mathrm{~min}$, decrease of the volume of affected limb was occurred by $39 \%$ and decrease of the thickness - by $20 \%$ comparing to the values of nontreated animals from the control group. Two hours after phlogogen introduction and during the whole experiment the inhibition of inflammation was observed in the animals treated with $5 \%$ experimental ointment. Antiinflammatory activity of ointment with ibuprofen slightly surpassed the effect of ointment with extract over the range $1 \mathrm{~h}$ to $2 \mathrm{~h}$ after the start of the experiment by the two morphological values.
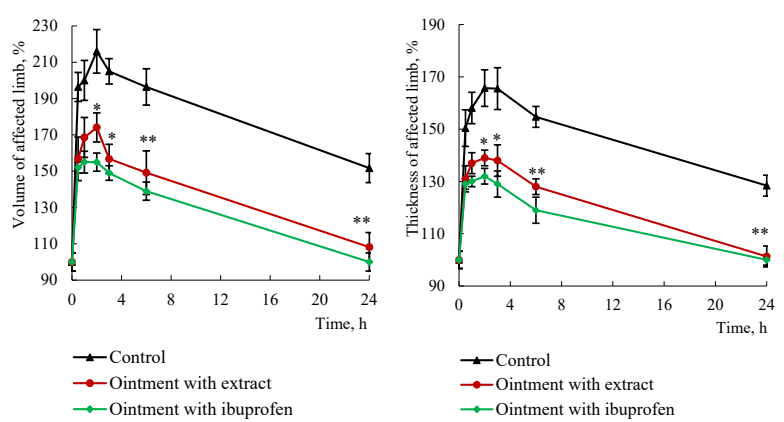

Figure 2. Anti-inflammatory activity of $5 \%$ ointment with extract and $5 \%$ ointment with ibuprofen using AITC-induced inflammation ( $\mathrm{M} \pm$ $\mathrm{m}, \mathrm{n}=5 ;{ }^{*} P<0.05,{ }^{* *} P<0.01$ comparing to the control group with inflammation).

\section{Discussion}

Various investigations showed that $70 \%$ ethanol was the most effective extractant for BASs receiving and at the same time it was the most effective for flavonoids extraction from C. aegagropila. For 14 days approximately $39.5 \mathrm{mg}$ of flavonoids per $1 \mathrm{~g}$ of dried alga as rutin equivalent could be extracted by maceration method. Presence of flavonoids in C. aegagropila allowed to use obtained dried extract for the ointment preparation with anti-inflammatory activity.

Polyphenolic compounds are secondary plant metabolites that exist as monomers, oligomers, polymers and they are presented as simple phenols, hydroxycinnamic and hydroxybenzoic alcohols, aldehydes and acids, flavonoids, lignans and their derivatives, tannins etc. Various studies determined that plant polyphenols have wide range of pharmacological activity including antiallergic (13), antiviral (14), anti-oxidative $(15,16)$, anti-inflammatory (17), vasoconstrictive and antimicrobial action (18). Different concentrations of ethanol $(40 \%, 70 \%$ and $96 \%)$ were used for flavonoids extraction. Quantitative total flavonoids content of the obtained extracts was spectrometrically defined using standard method in terms of rutin equivalent.

Anti-inflammatory activity of $5 \%$ ointment as dried extract equivalent was demonstrated using two models (short- and long-acting) of inflammation as phlogogenic agents. In both cases application of ointment led to inhibition of inflammation. Mechanism of antiinflammatory activity of phytogenic BASs is the polyvalent process and is conditioned by presence of the complexes of lipophilic and hydrophilic substances of various chemical structure. These substances had impacts on different pathogenetic chains of exudative stage of inflammation. Anti-oedematous action of the extract in our opinion is related to flavonoids effect on synthesis, deposition, release and transformation of the inflammatory mediators as well as capillary protective action of the phenol compounds.

Besides, it was indicated that animals that had therapy by application of ointment on the limb with inflammation, 
especially on the $2^{\text {nd }}$ day of the experiment in terms of carrageenan-induced inflammation and $2 \mathrm{~h}$ after AITC introduction could step on an affected limb even without pressing the limb, unlike non-treated animals. It is probably related to inhibition of inflammation induced by corresponding phlogogen. On the other side, it is related to action on TRP channels that are sensors of the pain stimulation. It should be noted that carrageenan is an agonist of TRPV1 receptors and AITC is an agonist of TRPA1 receptors (19). Various researchers indicated the mechanism of analgesic activity of phytogenic BASs especially with polyphenol structure that is implemented through the binding of these substances with corresponding TRP receptors (20). Therefore, it appears probable that flavonoids from C. aegagropila extracts might bind to TRP receptors by indicating the analgesic and anti-inflammatory activity of the ointment. Discovered pharmacological activity indicated the promising outlook of the tested alga and should be profoundly investigated further.

\section{Conclusion}

In consequence, it was revealed in research that $70 \%$ ethanol was the optimal extractant for extracting the total flavonoids from C. aegagropila by maceration method. Nevertheless, it was demonstrated that 5\% ointment based on obtained dried extract had anti-inflammatory activity on the models of carrageenan- and AITC-induced inflammation by inhibition of the inflammatory process on the two morphological values of affected rat's limb for the whole experiment, only slightly surpassed to the reference medicine in the relevant experimental duration. In sum, C. aegagropila extract possesses significant antiinflammatory action and might be used as an effective natural agent for inflammation treatment

\section{Authors' contribution}

IK conceived and designed the experiment; AA and SG performed the experiments; IK, AA and MN analyzed the data; IK, AA, SG and MN wrote the paper. All authors read and confirmed publication of the paper.

\section{Conflict of Interests}

The authors declare no conflict of interest.

\section{Ethical considerations}

Ethical issues including plagiarism, misconduct, data fabrication, falsification, double publication or submission have been carefully checked by authors. All experimental procedures conform to the guiding principles for research as recommended by "Guide for the Care and Use of Laboratory Animals" (NIH publication 86-23 revised 1985).

\section{Funding/Support}

None.

\section{References}

1. Mondal A, Maity TK, Bishayee A. Analgesic and AntiInflammatory Activities of Quercetin-3-methoxy-4'glucosyl-7-glucoside Isolated from Indian Medicinal Plant Melothria heterophylla. Medicines (Basel). 2019;6(2). doi: 10.3390/medicines6020059.

2. Cruciani S, Santaniello S, Garroni G, Fadda A, Balzano F, Bellu E, et al. Myrtus polyphenols, from antioxidants to anti-inflammatory molecules: exploring a network involving cytochromes $\mathrm{P} 450$ and vitamin D. Molecules. 2019;24(8). doi: 10.3390/molecules24081515.

3. Park SK, Park SJ, Park SM, Cho IJ, Park CI, Kim YW, et al. Inhibition of acute phase inflammation by Laminaria japonica through regulation of iNOS-NF-kB pathway. Evid Based Complement Alternat Med. 2013;2013:439498. doi: 10.1155/2013/439498.

4. Vázquez AIF, Sánchez CMD, Delgado NG, Alfonso AMS, Ortega YS, Sánchez HC. Anti-inflammatory and analgesic activities of red seaweed Dichotomaria obtusata. Braz J Pharm Sci. 2011;47(1):111-8. doi: 10.1590/S198482502011000100014.

5. Kyung J, Kim D, Park D, Yang YH, Choi EK, Lee SP, et al. Synergistic anti-inflammatory effects of Laminaria japonica fucoidan and Cistanche tubulosa extract. Lab Anim Res. 2012;28(2):91-7. doi: 10.5625/lar.2012.28.2.91.

6. Ramos RTM, Bezerra ICF, Ferreira MRA, Soares LAL. Spectrophotometric quantification of flavonoids in herbal material, crude extract, and fractions from leaves of Eugenia uniflora Linn. Pharmacognosy Res. 2017;9(3):253-60. doi: 10.4103/pr.pr_143_16.

7. da Silva LA, Pezzini BR, Soares L. Spectrophotometric determination of the total flavonoid content in Ocimum basilicum L. (Lamiaceae) leaves. Pharmacogn Mag. 2015;11(41):96-101. doi: 10.4103/0973-1296.149721.

8. Nesterkina M, Kravchenko I. Analgesic activity of novel GABA esters after transdermal delivery. Nat Prod Commun. 2016;11(10):1419-20.

9. Boiko YA, Kravchenko IA, Shandra AA, Boiko IA. Extraction, identification and anti-inflammatory activity of carotenoids out of Capsicum Anuum L. J Herbmed Pharmacol. 2017;6(1):10-5.

10. Onasanwo SA, Elegbe RA. Anti-nociceptive and antiinflammatory properties of the leaf extracts of Hedranthera barteri in rats and mice. Afr J Biomed Res. 2006;9(2):10917. doi: 10.4314/ajbr.v9i2.48891.

11. Meraiyebu AB, Olaniyan OT, Eneze C, Anjorin YD, Dare JB. Anti-inflammatory activity of methanolic extract of Hibiscus sabdariffa on carrageenan induced inflammation in wistar rat. Int J Pharm Sci Invent. 2013;2(3):22-4.

12. Nesterkina M, Kravchenko I. Synthesis and pharmacological properties of novel esters based on monoterpenoids and glycine. Pharmaceuticals (Basel). 2017;10(2). doi: 10.3390/ ph10020047.

13. Tewtrakul S, Subhadhirasakul S. Anti-allergic activity of some selected plants in the Zingiberaceae family. J Ethnopharmacol. 2007;109(3):535-8. doi: 10.1016/j. jep.2006.08.010.

14. Kamboj A, Saluja AK, Kumar M, Atri P. Antiviral activity of plant polyphenols. J Pharm Res. 2012;5(5):2402-12.

15. Shaikh R, Pund M, Dawane A, Iliyas S. Evaluation of 
anticancer, antioxidant, and possible anti-inflammatory properties of selected medicinal plants used in Indian traditional medication. J Tradit Complement Med. 2014;4(4):253-7. doi: 10.4103/2225-4110.128904.

16. Braca A, Sortino C, Politi M, Morelli I, Mendez J. Antioxidant activity of flavonoids from Licania licaniaeflora. J Ethnopharmacol. 2002;79(3):379-81. doi: 10.1016/s03788741(01)00413-5.

17. Gupta A, Chaphalkar SR. Anti-inflammatory activity of flavonoids from medicinal plants against hepatitis B vaccine antigen on human peripheral blood mononuclear cells. Asian J Med Pharm Sci. 2015;3(1):728-32.
18. Rigane G, Ghazghazi H, Aouadhi C, Ben Salem R, Nasr Z. Phenolic content, antioxidant capacity and antimicrobial activity of leaf extracts from Pistacia atlantica. Nat Prod Res. 2017;31(6):696-9. doi: 10.1080/14786419.2016.1212035.

19. Vriens J, Nilius B, Vennekens R. Herbal compounds and toxins modulating TRP channels. Curr Neuropharmacol. 2008;6(1):79-96. doi: 10.2174/157015908783769644.

20. Kravchenko I, Eberle L, Nesterkina M, Kobernik A. Antiinflammatory and analgesic activity of ointment based on dense ginger extract (Zingiber officinale). J Herbmed Pharmacol. 2019;8(2):126-132. doi: 10.15171/jhp.2019.20. 